\title{
Alternative recognitionals in person reference
}

Tanya Stivers

When people make reference to other persons they may make use of a range of referring expressions. As the contributions to this volume document, variations in the form of person reference may be based in general socio-cultural preferences or, within a given culture, may be based in individual or situational factors. One of the primary accounts for the use of one person reference form rather than another has been recipient design (Sacks \& Schegloff 1979). For instance, compare the use of a name (e.g., "Bill) to a description (e.g., "this guy"). The former conveys that the speaker assumes the recipient would be able to recognize the person by name whereas the latter conveys that the speaker assumes the recipient would not know the referent. Alternatively, the use of a name rather than a particular role description (e.g., "the girl that always sits next to you in the staff meetings") treats the recipient as being able to recognize the person and the selection of referring expression concerns how best to actually achieve recognition (See Sidnell, this volume for cases where reference forms are treated as not well fitted to the recipient).

In this chapter I argue that the use of one referring expression over another is not only about underlying linguistic or cultural preferences nor is it entirely accounted for in terms of the achievement of recognition. ${ }^{1}$ My central claim is that what I term "alternative recognitionals" do more than just refer to a person and that extra work is concerned with fitting the precise referring expression to the type of pragmatic/interactional action that they are otherwise performing. Since, in English, the default reference form for recognitionals is the bare name, a primary means for doing something more is to shift from this sort of "absolute" form to a form that associates the referent to another individual. I will argue that this effectively shifts the referent to being within another individual's domain of responsibility (or not).

In what follows I first outline the basic preferences in the domain of referring to persons in interaction that are relevant here. I then identify the unmarked forms of reference for initial references in English. The remainder of the chapter is concerned with exploring four primary types of third person alternative recognitionals in initial position. ${ }^{2}$ 
The chapter concludes with a discussion of the implications of these results for a theory of how people refer to persons in conversation.

\section{$1 \quad$ Background}

As Stivers, Enfield and Levinson note in the introduction to this volume, the structure of how speakers refer to persons in initial reference positions in actual interaction has not been much explored. Still, using English language data, two key principles have been shown to underlie person reference: a preference for using recognitional reference terms (i.e., terms that suggest that the recipient can and should be able to identify the individual being referred to) and a preference for minimization (i.e., the use of only one rather than multiple reference forms) (Sacks \& Schegloff 1979). When put into possible conflict, speakers display a preference for recognitionals over minimal reference forms as evidenced through a successive relaxing of the latter principle in favor of the former when necessary. These basic principles appear to hold in non-European cultures as well (See particularly the contributions of Brown and Levinson in this volume).

Both names and descriptions can be recognitionals under the Sacks and Schegloff rubric. Thus, "the girl who always sits next to me in staff meetings" and "Patty" are both possible referring expressions for a single speaker in a single conversation and both could, to a particular recipient, be recognitional forms. However, Schegloff (1996a) argues that in English names are preferred over descriptive recognitionals. Key evidence for this are cases where speakers who begin to use a descriptive recognitional, replace it with a name. For example, see Extract 1 (Schegloff 1996a p. 463).

\section{(1) Trip to Syracuse, 1:10-11 \\ 10 Charlie: hhhe:h .hhhh I wuz uh:m: (.) .hh I wen' ah:- (0.3) \\ 11 I spoke teh the gi:r- I spoke tih Karen}

Here, the two references are in bold, and the first is repaired from an incomplete but clearly projectable descriptive recognitional to a name (Schegloff, Jefferson \& Sacks 1977). 
A second key piece of evidence was a collection of cases where a speaker uses a descriptive recognitional and the recipient of this subsequently offers a name as an "upgrade" or replacement for the description. For example, see Extract 2 (Schegloff 1996a p. 462).

(2) Adato, 5:1

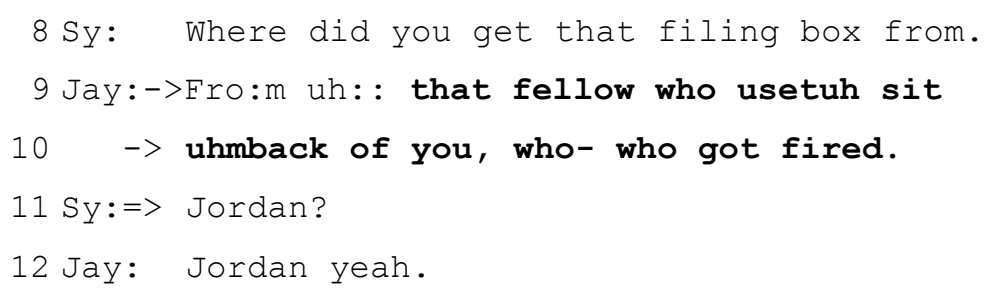

Here, Jay offers two descriptive recognitionals for the person to whom he is referring ("that fellow who usetuh sit uhmback of you," and "who got fired"). Sy offers the name "Jordan" as an upgrade and an alternative to those descriptions. The data Schegloff offers in support of this claim suggest one possible qualification which is that names are offered as upgrades to descriptive recognitionals in two main environments: 1) If the descriptive recognitional is treated as under-assuming the recipient's knowledge or 2) If the name is in some way suggested to be, or assumed to be, unavailable or inaccessible to the speaker. So, in the cases Schegloff shows and in my own data as well, replacements are typically offered when the descriptive recognitional is produced dysfluently thereby suggesting that its production is problematic. This is evident in Extract 2 above. Note the stretches in line 9 on "Fro:m" and "uh::" as well as the insertion of "uh". This appears to be a case of the latter situation where a recipient treats the speaker as having difficulty accessing the name.

The preferences outlined so far then document the ways in which speakers refer to persons so as to convey, "that nothing but referring is being done" (Schegloff 1996a, p. 439 but see Enfield this volume for a discussion of this). Now I want to focus on a second question Schegloff posed: "How do speakers do reference to persons so as to accomplish ... that something else in addition to referring is being done by the talk practice which has been employed?" (Schegloff 1996a, p. 439). This question was only partially dealt 
with in Schegloff's own chapter. There the primary means for addressing this question was with respect to the relative fit of reference form and position. Schegloff distinguishes between locally initial and locally subsequent with respect to both reference form and position. The unmarked usage then would be initial forms in initial positions and subsequent forms in subsequent positions. ${ }^{3}$ For instance, descriptive recognitionals and names constitute proto-typical initial reference forms and thus are typically used in initial position relative to that sequence or activity of talk. Pronouns are proto-typical subsequent reference forms and are typically used subsequent to some initial referring expression.

Schegloff observes that when a speaker uses a subsequent form in initial position, this conveys to the hearer that he/she is expected to know the referent (i.e., that the referent would be assumed to be "on the mind" of the other or could readily be activated" (1996 p. 451). Conversely, one use of an initial form in subsequent position is to "reconstitute the locally initial reference occasion by re-using the (same) locally initial form; it is not a re-mention, but the initial mention "for another first time"" (Schegloff 1996a, p. 455). In this way speakers can compete for first position in making a particular claim.

Returning to the use of initial reference forms in initial position, we also return to the how speakers do reference so as to show that they are "just" referring versus doing "more" than referring. This chapter focuses on this question beginning with a brief overview of how speakers refer to third persons in English by way of establishing which referring expressions can be considered marked and unmarked in these initial positions. We then turn to the interactional practice about which this chapter is primarily concerned. Finally, we will examine what this organization tells us about the principles underlying person reference as a system.

\section{$2 \quad$ Analysis}

2.1 Unmarked recognitional forms for 3rd person singular 
Schegloff (1996a) established that names, as a recognitional, were preferred over other forms of recognitional references. One form of evidence for this is sheer frequency of use (also see Sacks \& Schegloff 1979). In my own collection of 219 instances of initial singular recognitional references to third persons in English, I observed that there were three main types of unmarked recognitional reference forms: kin terms, descriptive recognitionals, and names. Kin terms were used for parents and grandparents of the speaker or recipient. Descriptive recognitionals were used when that is how a particular person would be known (e.g., "our dentist") and where names were either not known or problematic. Names were used for siblings, extended family (aunts, uncles, cousins), friends, colleagues, children and partners. ${ }^{4}$ Thus, these reference forms appear to be the forms for "just" doing referring. Most important for our present purposes, if, as far as I could assess, a name was possible, it was used $93 \%$ of the time. Possessed kin terms were used in only $14 \%$ of all canonical cases, but where they represented the unmarked form, they were used $100 \%$ of the time.

Most of this work was done on English data, but these generalizations and the practice being reported on in the rest of this chapter appear to work the same way in a number of other languages including Danish, Dutch, Italian and Spanish. Therefore, some examples from these languages are included here.

\subsection{Departures from unmarked 3rd person recognitionals}

There are a variety of ways to depart from an unmarked person reference. The prosody with which a particular form is delivered can indicate that "more" than simply referring is being done. For instance, when a woman tells a story of running into an ex-boyfriend who asked her whose truck she was driving, she reports having responded with a very prosodically marked (something like a taunt) "my boyfriend's". On the one hand, as a non-recognitional form, this is not at all marked. That is, references to persons unknown by the addressee appear to be commonly done through the speaker or addressee if at all possible. However, to the reported addressee, her ex-boyfriend, this is specifically reported as having been delivered in a provoking manner to accentuate her new relationship. 
Related to this, unmarked forms are sometimes reduced (e.g., "Julie" reduced to “Jules") or expanded (e.g., "fat ole Vivian", "poor ole Gladys" or full names where the use of a single name would do). These changes certainly appear to be doing additional interactional work, but they accomplish this work from within a single category (e.g., the name reference form) rather than through a shift in category (e.g., from name to kin term). I will be most centrally concerned with categorical shifts in reference form in environments where the unmarked category of reference was entirely possible. This type of departure from the default is what I term an alternative recognitional. This reference form is an alternative to the default category (whether that be a name or a kinship term). The most common scenario is the use of a descriptive recognitional instead of a name. To be an alternative recognitional:

1) the speaker must know the unmarked form (e.g., the name).

2) The speaker must a) assume the hearer knows the unmarked form and b) to assume that the hearer would assume the speaker knows it.

3) The form used must still be recognitional for the hearer.

Alternative recognitionals, as would be expected of a marked expression, comprised only $6 \%(n=13)$ of the original collection of person references. For this study, these cases were subsequently supplemented with a further 15 cases in order to have a total collection of 28 instances on which the present study is based. Across these data, there were four types of alternative recognitionals: 1) Recipient associated; 2) Speaker associated; 3) Demonstrative prefaced; and 4) "in the know" references. In what follows I examine several instances of each type of alternative recognitional. I show that regardless of type, alternative recognitionals are a way for speakers to not only refer to persons alongside accomplishing social actions but through the use of a marked form of person reference speakers also accomplish and/or account for particular social actions through the form of reference. I then draw some conclusions about the relative differences accomplished by the different types of alternative recognitionals (i.e., recipient vs speaker associated).

\subsubsection{Recipient associated: "Yer sister"}


As mentioned earlier, within the environment of two interlocutors who both know the referent by name, names are the unmarked form of reference for friends, colleagues, and acquaintances as well as for siblings, extended family, children and partners. One way in which interactants mark doing something more than just referring to one of these people is to associate their referent to their addressee when no such association would normally be done. For example, see Extract 3. Nicole is a hair stylist and owns her own salon. Her mother has just come in the door and is here initiating an interaction with Nicole.

Nicole's son (and thus her mother's grandson) is having a birthday party that evening in the local park. Shortly prior to Nicole's mother arriving at the salon (and unbeknownst to her), Nicole's aunt (her mother's sister) had called to ask Nicole whether she had set things up for the boy's party. In this context the mother moves into a proposal about where to buy items for the birthday party (lines 2-3/4).

\section{(3) HS 5 7-23-03 T1}

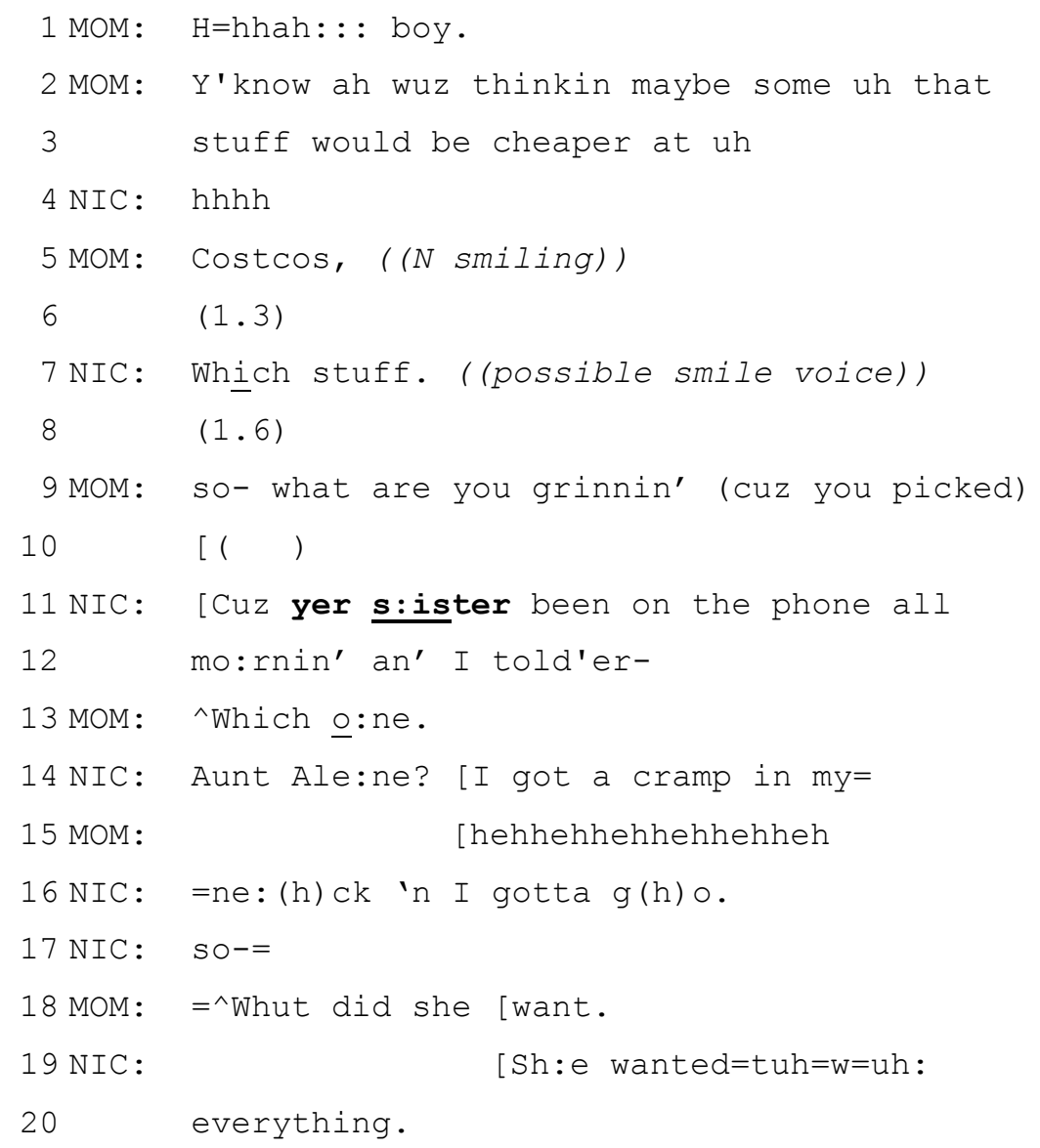




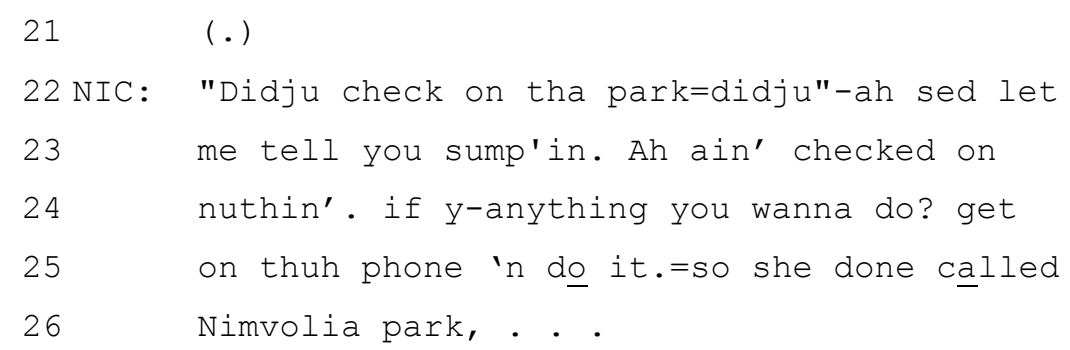

The alternative recognitional is Nicole's use of "yer s:ister" to refer to her own aunt. As an extended relative the use of her name "Alene" or an expanded "Aunt Alene" would have been the unmarked form of reference. "My aunt" and "your sister" are marked because both categorically depart from the unmarked form (i.e., name). Also, because this is the addressee's sister and the speaker's aunt, there is no question that the name is known to both interactants (indeed at line 14, Nicole names the aunt). This case provides ready evidence for the way that departures from unmarked referring expressions can cause interactional problems. The use of "your sister" rather than "Alene" is ambiguous to the addressee, and leads to an initiation of repair (Schegloff et al. 1977) in line 13. The speaker is certainly aware that her addressee has multiple sisters, but nonetheless uses this form. The obvious question is what this form allows her to do that "Alene" does not particularly lend itself to.

In this interaction, the mother proposes buying "that stuff" for the birthday party at a "Costco's," store. Before the proposal is complete Nicole is responding to the action with an audible sigh (line 4) and then a smile. Her verbal response is delayed (line 6) but she then initiates repair on "that stuff" asking "Which stuff." thereby problematizing the mutual availability of the indexical reference. The repair contradicts Nicole's just prior visible and vocal behavior which suggested a negative stance towards the proposal or at least towards the bringing up of the topic of where to buy things for the party which suggests that she understood the reference to "that stuff". And it is precisely this that Mom asks Nicole to account for in line 9 with “what are you grinnin' (cuz you picked) ( )". It is in Nicole's account that the alternative recognitional figures.

The alternative recognitional is embedded in an account for Nicole's problematic response to Mom's proposal. This account is also a complaint. This is most visible in the use of "all mo:rnin"" to refer to the length of the call. This formulation is extreme 
(Edwards 2000; Pomerantz 1986; Sidnell 2004), and that at least partially accounts for the complainability. The use of an alternative recognitional conveys that it is the referent who is responsible for the complainable action. Thus, the complaint is against the referent ("yer sister").

However, this is not only a departure from "Alene" but it is also a particular use of this type of alternative recognitional: one that explicitly associates the referent to the addressee (rather than, e.g., to the speaker). In this sense the source of the complaint is connected to the recipient in a position just following an action of proposing what to do about the birthday party. The use of this person reference form does far more than simply refer to Alene. It conveys that what she has been on the phone talking about is the very topic that Mom brought up on entering the salon (i.e., the party) and that this could be expected given the relationship between the aunt and the mom (i.e., that they are sisters), and that the mother can well sympathize with what would be involved in such a phone call because of that sibling relationship. Although precisely what was discussed is not treated as understood by Mom (note the inquiry at line 18), that lines 11-12 convey substantial information is clear in Mom's laughing response in line 15 which is delivered as she doubles over with laughter. Note that although there is a repair sequence, once the referent is clear, the mom's response to the account/complaint is provided immediately and so I am treating it as a response to the account/complaint.

To sum up then, this instance of an alternative recognitional offers evidence that when speakers depart from the use of a default referring expression, they convey that they are doing more than just referring. This form is a better fit between the referring expression and the action being accomplished (here a complaint) than a name since the latter, in and of itself, is neutral with respect to the action being done. Thus, the use of an alternative recognitional can be used specifically to move the accomplishment of a social action from something that is separated from person reference to something that is being done through person reference.

Extract 4 is similar. In this case Emma and Lottie (two sisters) are talking on the phone. Emma is reporting on a call she made to her daughter Barbara during which she told Barbara that her husband (Barbara's father) had left her. Importantly, both in calls to Barbara and in other similar contexts, references to parents are generally done as names 
using "Mom" or "Dad" or a variant of this such as "Daddy", "Mama" etc. Here the alternative recognitional is used and like Extract 3, it is the recipient associated form "Yer FATHER" (line 10).

(4) NBIV.10.R*Rev 31.29

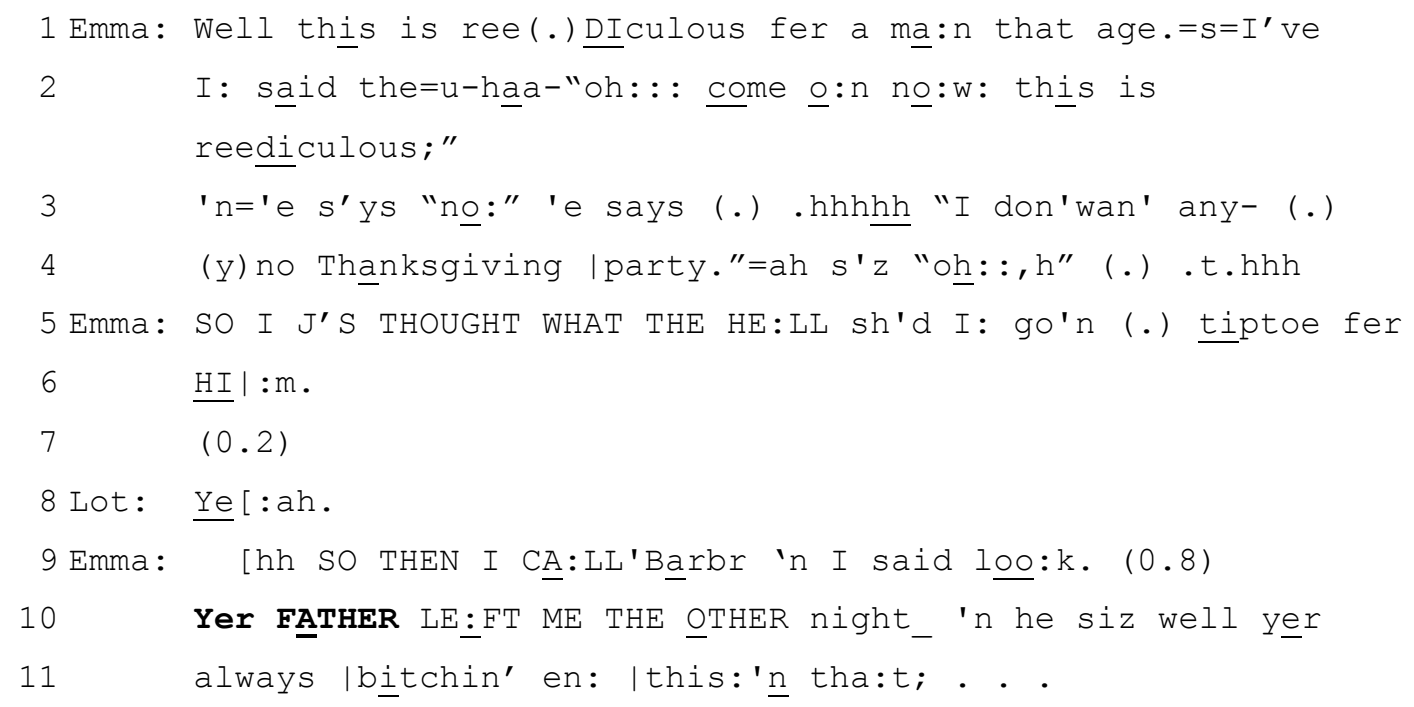

In lines 1-6, Emma is complaining about her husband who has said that he does not want to have their children over for Thanksgiving and has left his and Emma's vacation home at the beach in a huff stating that he will not return for Thanksgiving at all. Emma then faces the prospect of canceling plans with family and revealing their marital problems. In this context of complaining, she reports another complainable: that she had to then call their daughter Barbara to tell her that this was going on and that Thanksgiving might not proceed as planned. This itself, in its original context to Barbara, is hearable as a report of trouble (Jefferson 1988). But it is not a trouble without blame. Here it is specifically a trouble that is being blamed on Bud, the husband, and what is highlighted is the recipient's relationship to the referent "Yer FATHER" (line 10). That it is a complaint about her husband is carried by the use of the alternative recognitional rather than the default "Dad". Whereas "Dad" would have been neutral as to blame for the troubles being told, the alternative recognitional specifically conveys that there is a complaint against him. 
Similar to the previous case, the use of "Yer FATHER" associates the referent to the addressee. In this way Emma, similar to Nicole in Extract 3, places the referent in the domain of responsibility of the addressee. By doing this, Emma also begins to coimplicate Barbara in the resolution of the trouble. And in fact, Barbara is subsequently asked to intervene with her father and does succeed in getting him to agree to attend the dinner. We can see this issue of co-implication dealt with on the surface of the interaction in Extract 5.

Here, a co-present Italian family including Enzo, his mother, grandmother, grandfather and great-grandmother (all on the mother's side of the family) as well as his grandmother's brother is visiting. Enzo is preparing to leave the house and, in terms of overall structural organization, this is a structural place where arrangements for a next visit to "i nonni" (the great-grandmother and her son) might be thought appropriate. In this environment, Enzo instead addresses his mother with a directive to tell his brother Roberto to decide when he would like to plan the visit to their older family member (which according to precedent, should involve both brothers). Embedded in this directive is an account for his inability to plan the visit. Also, the reference to his brother in this turn is done with an alternative recognitional all'altro tuo figlio, or "your other son" (line $3)$.

$$
\text { Rossano LFRMVDN14Dec0201 00:03:18 }
$$

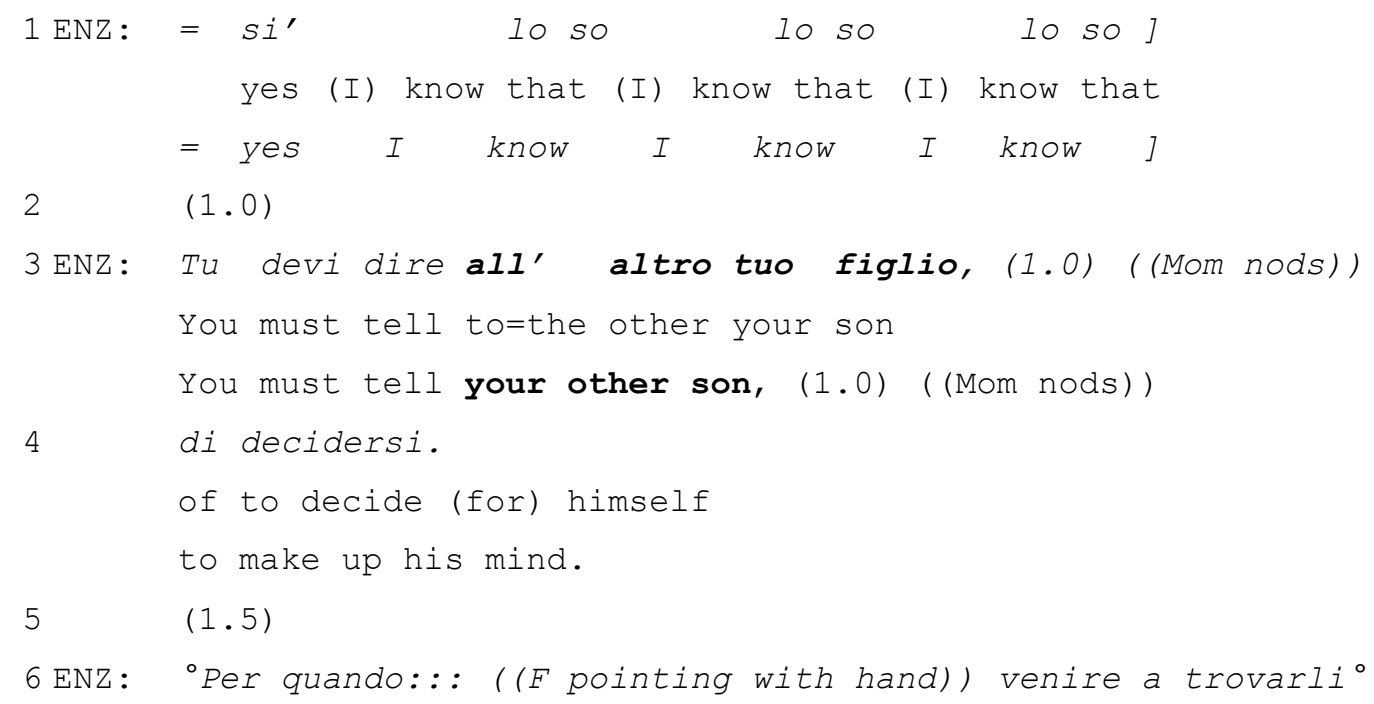




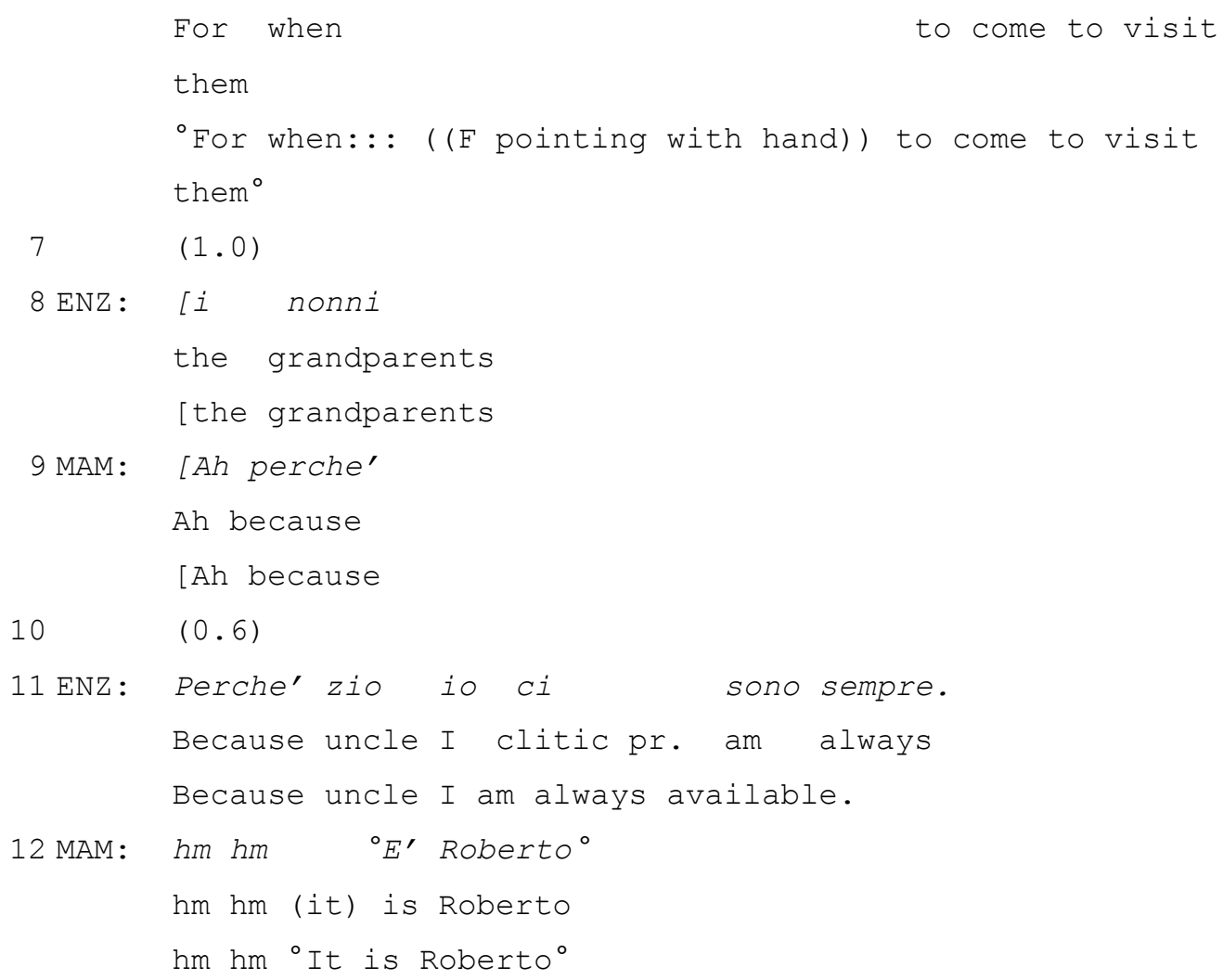

In this case, similar to Extracts 3 and 4, there are two issues: 1) the categorical shift from the unmarked name to an alternative recognitional, and 2) the use of a recipient associated form of alternative recognitional. Also similar to the other cases, whereas a directive using the unmarked name would have been neutral with respect to attributing responsibility for the problem, the alternative recognitional conveys that the problem rests with the brother. Additionally, the format associates the referent to the addressee, their mother. This places the referent in the addressee's domain of responsibility which conveys that she knows the problem and also co-implicates her in finding a solution. And here, the mother validates Enzo's complaint by explicitly blaming his brother (line 12).

So far this section has examined cases involving complaints. Although alternative recognitionals are commonly used in complaints, this is not exclusively the case. See Extract 6. Here, several couples are having dinner together. Not everyone is seated at the table yet, and Stanley approaches the table observing that two chairs are free -- one on either side of Deborah. Deborah's partner is not yet seated. All of the guests are friends and thus knowledge of names is not at issue when Stanley asks Deborah "Where's uh: 
Where's your guy sittin(g)." (line 3). This question is preliminary to his taking a seat and clearly the import of the answer to this question is whether he can take the seat that he has approached or not. Embedded in the question is the use of "your guy" as an alternative recognitional in place of his name, Clive.

(6) Kara 00.35 ((as Stanley is preparing to sit next to Deborah))

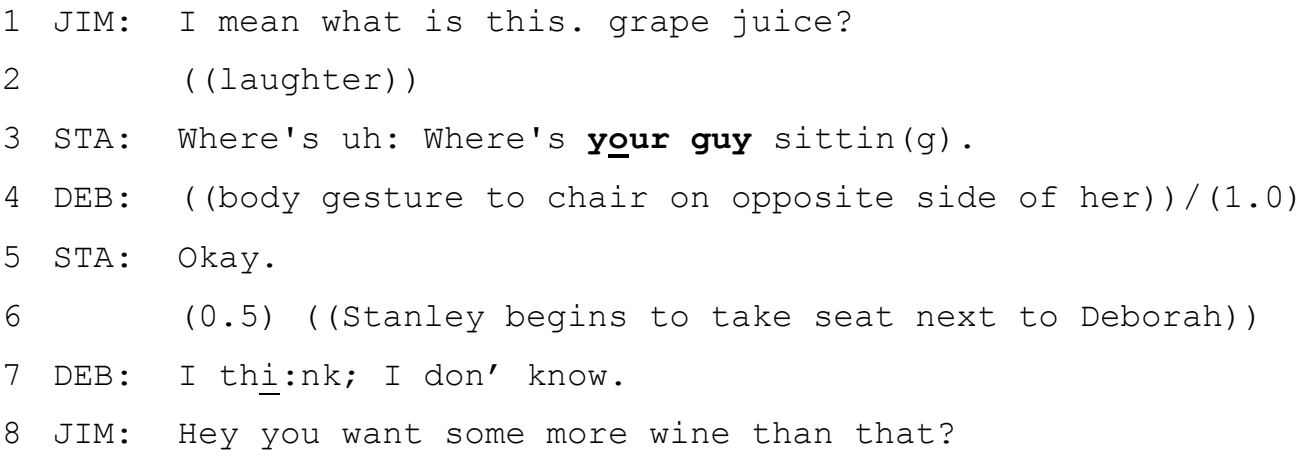

With "your guy" Stanley conveys that through his request for information he means to minimize his intrusion into the "couple" of which Deborah is part. He is not asking where "Clive" is sitting where this would be neutral with respect to Clive's relationship to Deborah. Rather, asking where "your guy" is sitting explicitly associates the referent to the addressee and in this way shows the question to be not just one about whether Stanley can sit in a particular seat but as one that actively respects their rights as a couple to sit together. In addition, through the associated reference form, Stanley treats Deborah as in a position to respond to this question: as having a measure of responsibility for "her guy". This action is accomplished through the use of an alternative recognitional rather than being done alongside a reference to a third person. ${ }^{5}$

This section examined four cases of alternative recognitionals where the categorical departure is from a name to a recipient associated form. In each case I have argued that by using an alternative recognitional, the speaker conveys that he/she is not only referring to the referent but is also doing some particular action through the referring expression. Further, I have argued that with the recipient associated form of alternative recognitional, the speaker invokes the social relationship between the recipient and the referent and by intimating that the addressee has some measure of responsibility for the 
referent, co-implicates him/her in the action either as a co-member of the class of responsible party (e.g., Extracts 3, 4 and 6) or as someone who can intervene (e.g., Extract 5).

\subsubsection{Speaker associated: "My honey"}

Referents are also sometimes associated with the speaker. For instance, see Extract 7. Here Nicole and Shauna, hair stylists at Nicole's shop, are talking. There has been a lapse in the conversation during which Nicole is styling a client's hair and Shauna is sitting at the next styling station. Nicole announces that her boyfriend's birthday is on Sunday. Nicole and Shauna are close friends, and earlier in the conversation Nicole has referred to her boyfriend Rick using his name unproblematically in a story to Shauna. Here though he is referred to using the alternative recognitional "my honey".

(7) HS5 7-23-03 T2 4:00

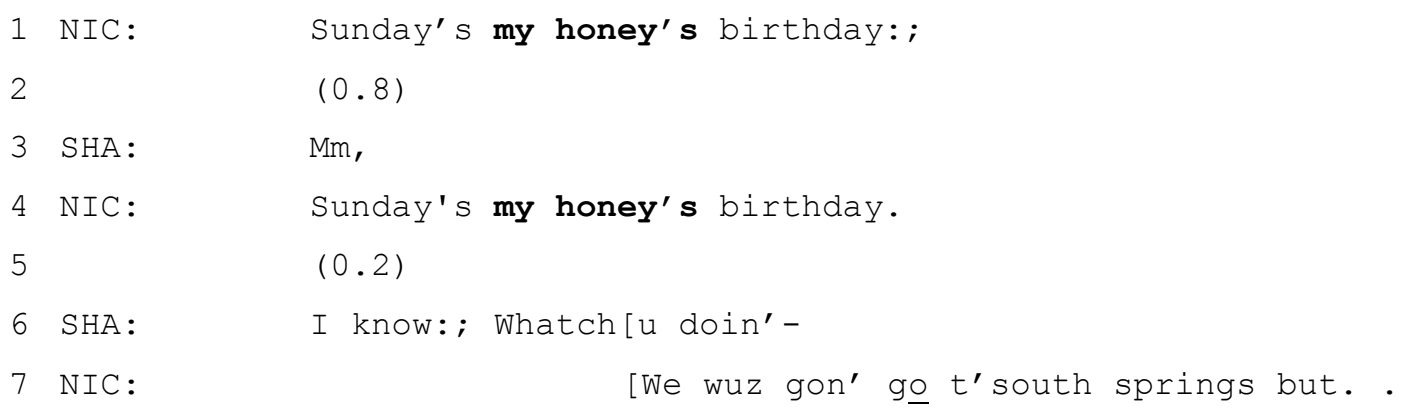

In this case both the announcement (line 1) and the repair of it (line 4) involve the same alternative recognitional. Although the description "honey" is not as transparent as "boyfriend", "father", or "sister", it is, I would argue, nonetheless clearly identifying a single individual. Although terms of endearment are used to identify children and pets (e.g, "my baby", "our good little boy"), "honey" is typically reserved for partners. Although repair is initiated on the turn in line 3, Nicole does not treat the alternative recognitional as the problem and rather simply repeats the turn. Shauna appears to then understand the reference unproblematically (line 6). 
The alternative recognitional is tied to the action the speaker is involved in. By announcing her boyfriend's birthday with this particular referent, she highlights the announcement as positively valenced: something to be celebrated, rather than a chore to be handled. Additionally, through the use of the possessive "my", the speaker associates the referent to herself, thereby highlighting their relationship. This is different from the cases shown in the prior section since there, even in cases where there was a relationship to the speaker, this was not the one that was made explicit. And, across all cases, these contrast with a reference form that is neutral with respect to associating the referent to either the speaker or addressee (e.g., a name). Similar to the addressee associated cases where some measure of responsibility was attributed to the addressee, here this responsibility is attributed to the speaker. This is evidenced in Shauna's response "Whatchu doin'-“" where there is a presumption that the speaker will be involved in doing something for her boyfriend.

In Extract 8, Nicole is reporting on another birthday, her son's. In most mentions of him, he is referred to by name (De Shaun), but here he is referred to with an alternative recognitional, "mah baby". Just prior, Nicole was on the phone, and here Nicole initiates a resumption of an earlier outlining of what they are doing to celebrate the birthday (line 2) and then accounting for why they are not doing more (lines 3-4). The account is that she has been busy and forgot the birthday entirely. Here she reports this as an enactment of remembering. See line 5 with “.hHH O^${ }^{\wedge} \mathrm{H}$ : mah baby's birthday iz on Wednesday.”.

HS_5_7-23-03_T1 46:20

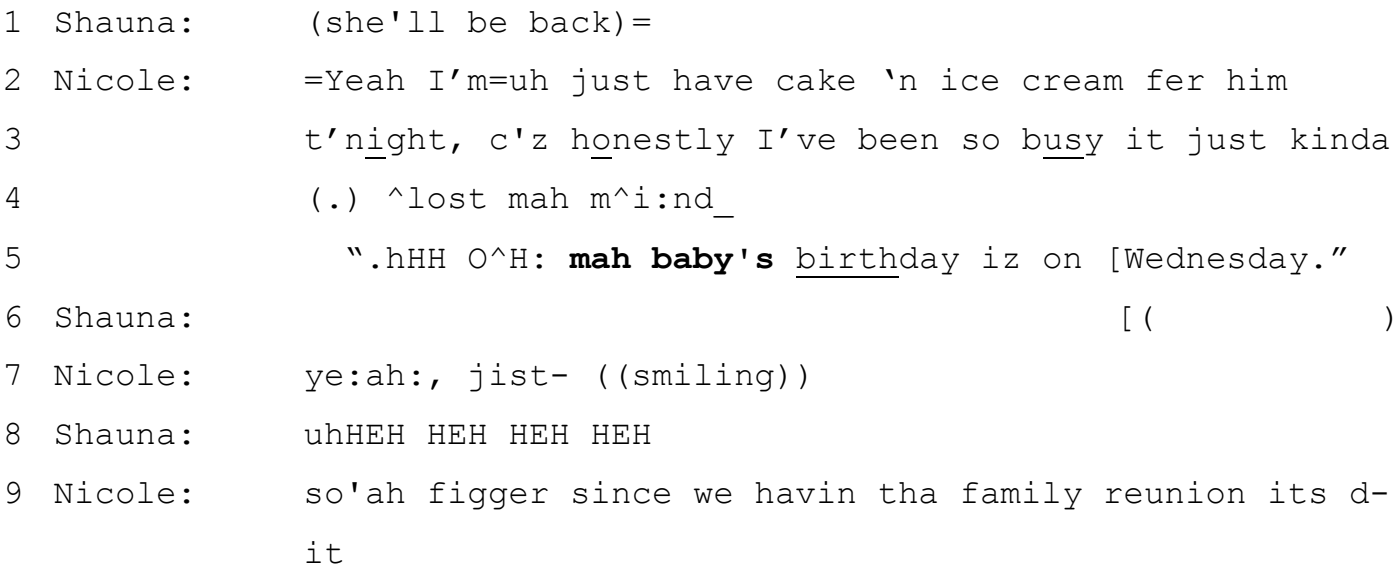


In the design of her report, Nicole conveys the valence of this report, and thus gives information about how her recipient could affiliate/disaffiliate. That is, following a report of bad news (e.g., forgetting an unexpected and time consuming chore) affiliation would be done differently than here: following a report of forgotten but nonetheless good news. It is not only good news but also news that requires something to be done about it, and this is further conveyed with the speaker possessive "mah" as in Extract 7. And, as in other cases, the possessive explicitly associates the referent to the speaker. Additionally, the term "baby" rather than "son" highlights the referent's dependence on her, and this places him within her domain of responsibility.

This section has offered two additional instances of alternative recognitionals. Taken together with the instances shown in the first section, all cases support the argument that a departure from the unmarked person reference conveys that more than simply referring is being done through the talk. In all cases the extra work has been to fit the referring expression to the action that is otherwise being implemented through the talk, and in all cases the referring expression assists with the implementation of the action (e.g., the complaint or the announcement) and/or it works to account for the action (e.g., why the complaint is being lodged). In all cases too, there is an issue of responsibility such that by associating the referent to the addressee or to the speaker, the speaker conveys that the referent is within that party's domain of responsibility.

\subsubsection{Demonstrative prefaced descriptions: "That next door neighbor"}

The third alternative recognitional format involves the use of a demonstrative prior to a description. Unlike the previous two types of alternative recognitionals, demonstrative prefaced descriptions do not associate the referent to either the speaker or the addressee. However, in initial position, they do indicate whether or not the addressee should know who the referent is (Ariel 1990; Schegloff 1996a). Whereas a reference to "this girl at work" suggests that you either do not know or do not need to know who the referent is, "that girl" suggests that you know who I am referring to (Auer 1984). ${ }^{6}$ However, it may convey more than this (See Levinson, this volume and 2005). 
With respect to objects, Enfield (2003) uses Lao date to argue that speakers use the demonstrative determiner nan/ "that" in environments where the referent is outside of the speaker's interactional focal area or "here-space". Conversely, nii/“"this" is used in contexts where there is either no clear "here-space" boundaries or when the referent falls within the "here-space" of the speaker. This analysis is relevant here if we extend Enfield's concept of "here-space" to include not just immediate interactional focus but also his/her domain of responsibility.

As an initial examle. See Extract 9 where a family is having dinner together. The father begins a complaint about their neighbor using the alternative recognitional. As with all other cases, here there is reason to believe that the speaker does know the name of the neighbor he refers to, but even if this were not the case, there is a shift from the likely default "our next door neighbor" to "that next door neighbor". In both recognitional and non-recognitional references it is common for speakers to associate referents to themselves if a name is not possible (e.g., "my colleague"; "my friend"). Here, then that association would be done with "our". Instead, "that" is being used. This alternative is critical.

(9) Stew Dinner 28.35

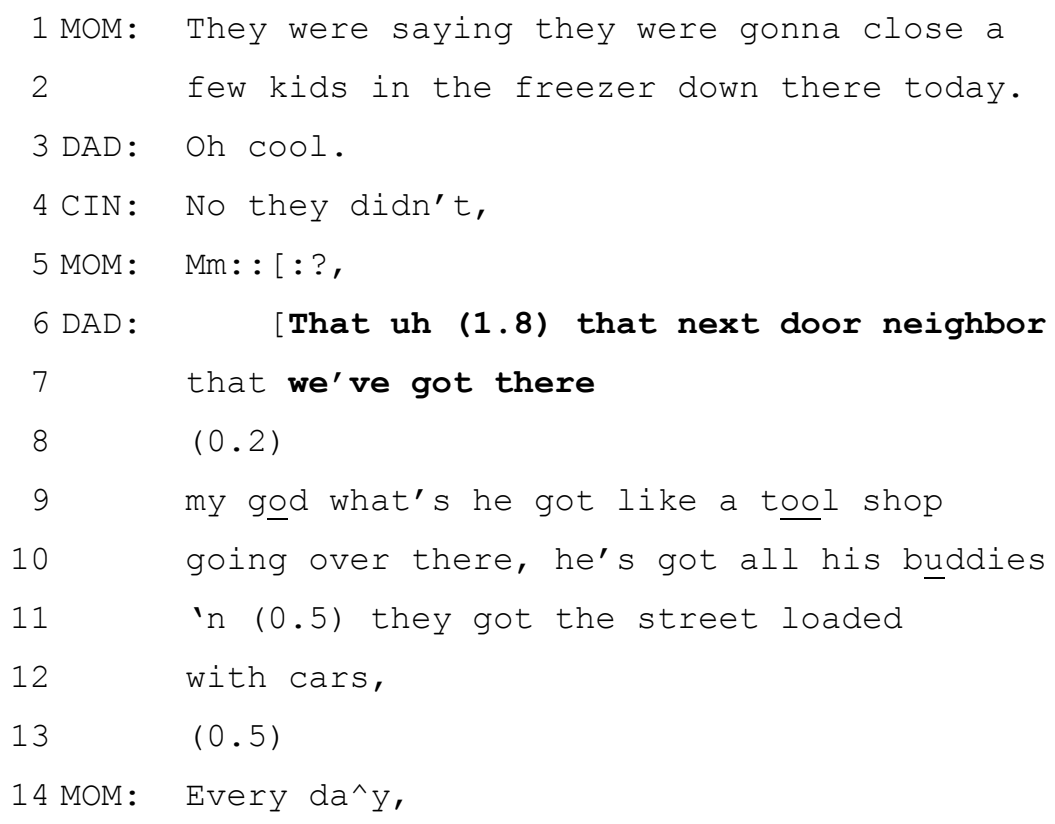


Once again the alternative recognitional is used to support the action that is being implemented in the turn in a way that is not done through the use of the unmarked reference form. Here again, that action is a complaint, and this is conveyed early on through the use of "that". The context also supports the recipient's hearing of this as a complaint since here the girl (Cindy) has been behaving badly at the dinner table and has been told to stop. Extract 9 begins just after this where, on the topic of bad behavior, the mother states that "They were saying they were gonna close a few kids in the freezer down there today" referring to her daughter and the rest of her school class who had been on a field trip to a local restaurant this morning.

This sequence reaches possible completion at line 5 with a confirmation of the claim originally offered in lines 1-2 in response to Cindy's rejection of the claim at line 5. Here Dad begins his complaint. Note that while "that" projects a possible complaint, "next door neighbor" in and of itself does not convey that there is a problem with the referent, but the use of "that" does suggest this. In this way the demonstrative determiner argument proposed by Enfield works well if we extend the concept of "here-space". When Dad refers to him as "that next door neighbor", he asserts that he is not within his "here-space" and thus distances the referent from both himself and his wife. The "that" helps this action to be heard as a complaint prior to any complaint actually having been articulated. Furthermore, the attachment of "that" to the referent conveys that it is the referent who is the complainable (see also Sacks, 1992, vol. II p. 502-503). This is the case here as the complaint itself shows. The complaint is that "he has got like a tool shop going over there, he's got all his buddies 'n (0.5) they got the street loaded with cars," And the person responsible for this is "that next door neighbor that we've got there."

There is further work done with expansion "that we've got there" since this portrays the neighbor as still further outside the interactants' domain of responsibility. Dad does not refer to him even as "that next door neighbor of ours". Moreover, embedded in the complaint is an account for the culpability of the neighbor: he has the tool shop going; the buddies are his; and his buddies have the cars that block the street.

Unlike the speaker/addressee associated cases shown in the previous two sections, here the demonstrative determiner does not place the referent in anyone's domain of responsibility. Rather, it affirmatively places the referent outside of the speaker and 
addressee's respective and collective domains of responsibility which is a type of disassociation. Thus, secondarily the use of this form helps to affiliate the speaker with his wife with respect to the referent.

Extract 10 shows a second example. Nicole and Shauna are again talking in the hair salon. Nicole has just been complaining about her father and some of her living situation difficulties due to his role in her life. This complaining is finishing up in lines 1-4 boundaried by the use of several different idiomatic expressions marking the end of the topic (Drew \& Holt 1995, 1998; Holt \& Drew 2005). These are: "You know how mah daddy is,"; "jist that's i^t."; “^Take it fer what it’s worth."; and arguably “"'ah'm not fee:lin him." (though what that precisely means is unclear). There is then a shift to a slightly different topic in lines $4 / 6-8$. The transition is to a telling about her father which, in the course of its production is revealed to be both a complaint and to provide a concrete instance and thus evidence for him as complaint-worthy. The alternative recognitional is "that nigger" rather than the unmarked name "Rick" to refer to Nicole's boyfriend. This reference occurs in reported speech attributed to her father, and there is no doubt that her father knows her boyfriend's name.

(10)

HS 7-23-03T2 00:20

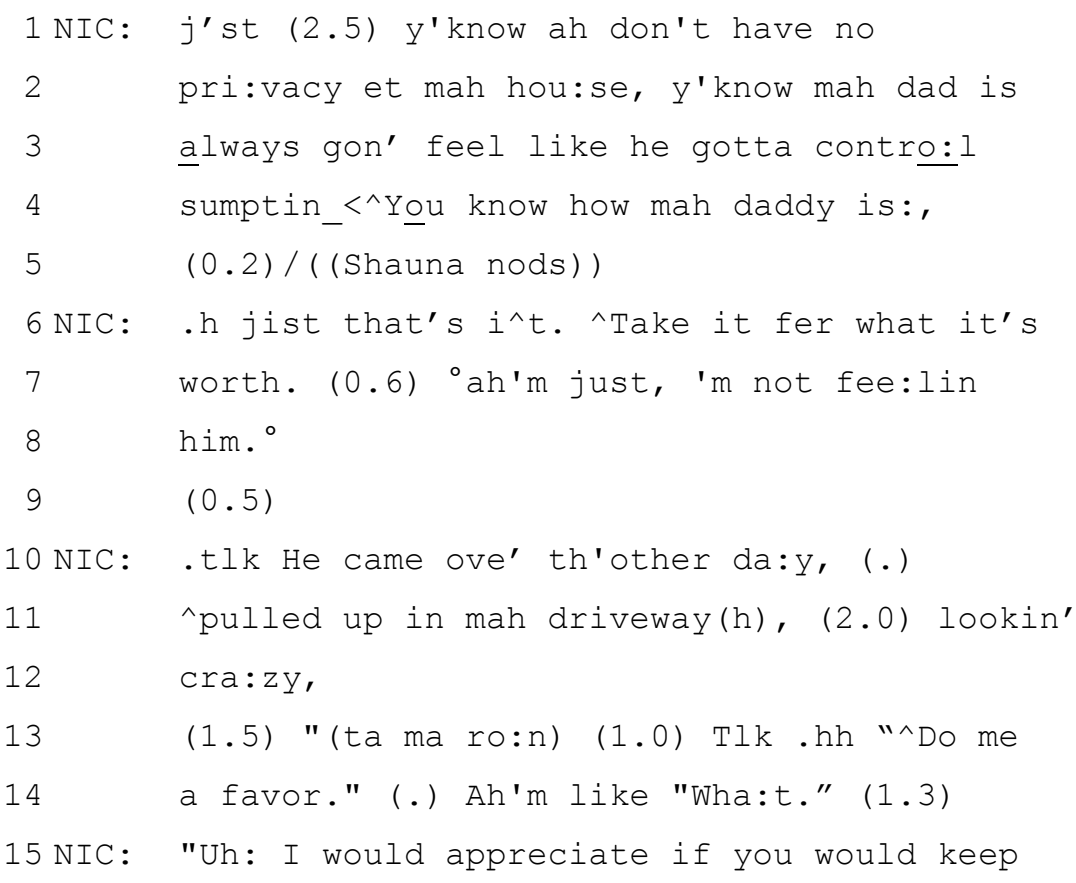




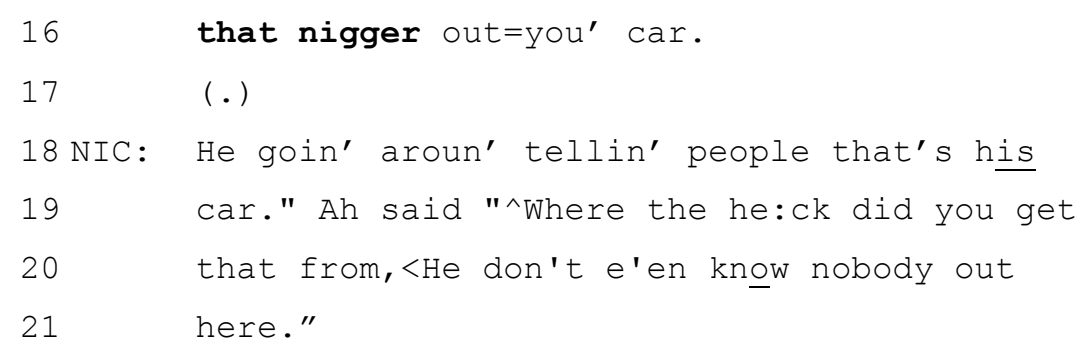

This case is complicated due to the reported speech, but this is also particularly revealing. The telling begins in line 10. The context of complaining about her father, similar to the "bad behavior" topic in Extract 9, supports an analysis of this as on its way to a complaint. And, there is no marking of this new sequence as topically disjunctive (Drew $\&$ Holt 1995; Jefferson 1984). Finally, it affirmatively projects some continuation of the same topic through the anaphoric reference to her father while nonetheless beginning a new sequence with “.tlk He came ove' th'other da:y,". The telling begins with the context of the reported speech that was delivered. Revealed in this is that the reported speech took place in Nicole's driveway, and that he was "lookin' cra:zy," (lines 11-12). The reported speech then begins with something that is not understandable but is delivered like a summons "(ta ma ro:n)" and then a reported speech pre-request: “^Do me a favor." (lines 13-14) (Schegloff 1980; Schegloff et al. 1977). After a reported go ahead, Nicole reports her father to go on to make his request (lines 15-16). Embedded in this request is a complaint by her father. This may be partially conveyed through the request sequence and the pre-sequence which may project the base first part action to be delicate (Schegloff 1980). Additionally though, the use of a marked person reference conveys first that this is a complaint action embedded in the request and also an account for the complaint and thus furthermore for the request that is the vehicle for the complaint (Schegloff in press). That this is the case is still further evidenced in that what Nicole reports her father to go on to do is to explicitly account for his complaint (lines 18-19). And with this account he simultaneously accounts for his use of this sort of person reference form.

Here then, similar to other cases we have seen across this and prior sections, the use of an alternative recognitional is fitted not just to the recipient in terms of achieving recognition, but is fitted to the action. Whereas the unmarked referring expression is 
neutral with respect to the action in which it is embedded, alternative recognitionals differ precisely because they are designed to assist in conveying the action and/or accounting for the action in which they are embedded. Here, like several other examples, the action is a complaint. It is both a complaint in the reported speech request (by Nicole's father) and by the actual speaker (Nicole). In terms of footing then both the author and the animator are involved in the doing of a complaint (Goffman 1981). And once again it is the person being referred to through the alternative recognitional who is targeted as the source of the complaint.

The demonstrative determiner prefaces shown in this section convey that the action being done is a complaint. Drawing on Enfield (2003), this appears to be managed through the use of "that" conveying the semantic information that the referent is outside of the speaker's "here-space" but where the concept of "here-space" is broadened to include domain of responsibility. In this way with the demonstrative determiner, the speaker disassociates the referent from both the speaker and the addressee.

\subsection{4 "In the know" references: "The lady mayoress"}

The final type of alternative recognitional that I will discuss here is recognitional references that require substantially more common ground (Clark 1996) than other cases in order to achieve recognition. Most commonly these references involve a definite determiner followed by a description that requires the hearer to simply "know" who this is. However, they can also involve the use of a name or title in a way that also requires the hearer to know who the individual is: a kind of "code" for the person. As an initial instance, see Extract 11. Here Billy has called Edgerton on the phone to congratulate him on becoming mayor. This extract comes after Edgerton has initiated the end of the call with arrangements as to when they will see each other next. Here in lines 1-3 he proposes closure of the call with a return to the original reason for the call (Button 1987): " $\mathrm{f}$ 'm both'v us many thanks fuh calling?" (line 3). The alternative recognitional is the use of “the lady mayoress" rather than Edgerton's wife's name which Billy most certainly knows. 
(11) Heritage 0III-1-5 9.23

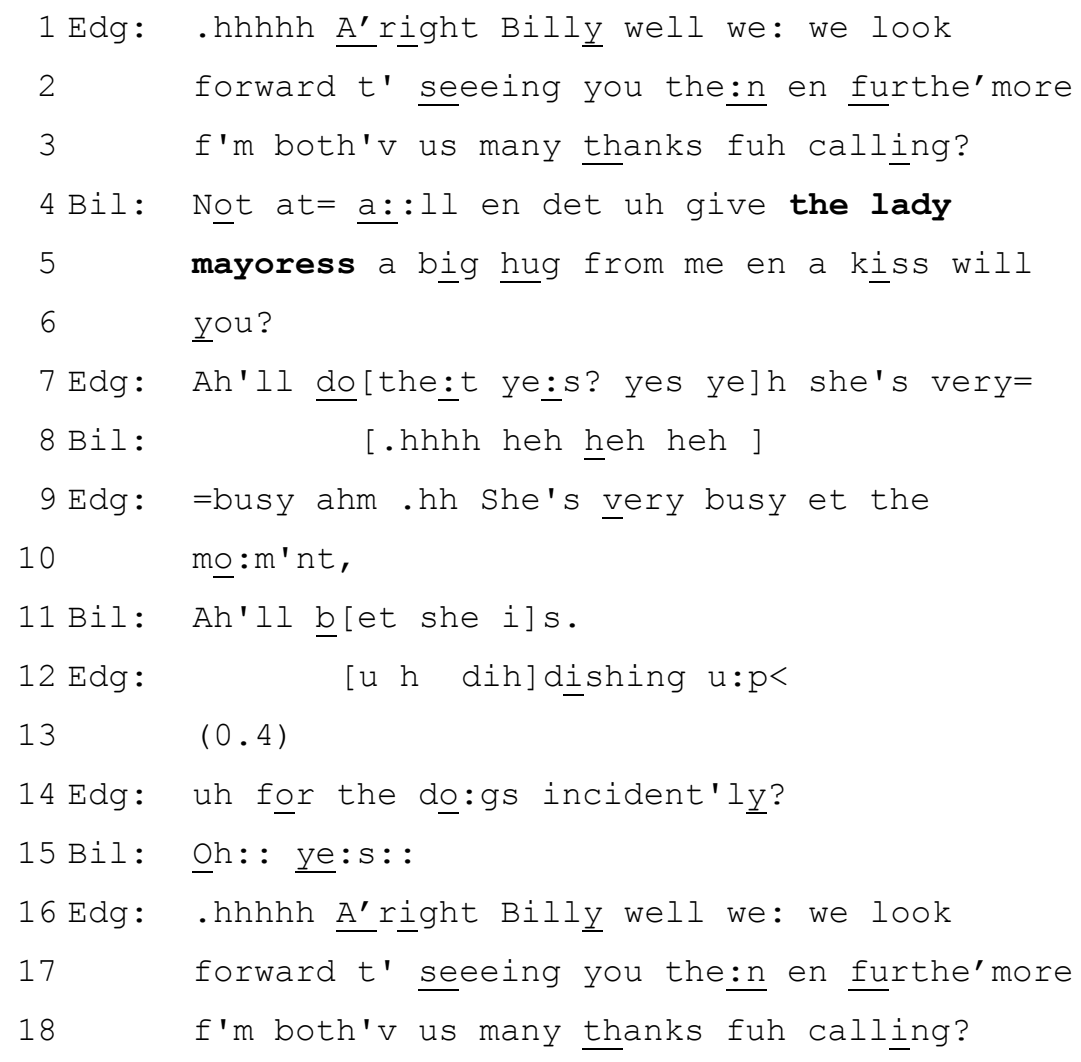

In response to the proposal to close the call, Billy first receipts the "thanks" with "Not ata::1l" (line 4) and then directs Edgerton to give his wife a hug and kiss. Embedded in this directive is the use of the alternative recognitional. The use of "the lady mayoress" indexes that they are still in closings by invoking the reason for his call: to congratulate Edgerton. Through the reference to "mayoress", the alternative recognitional helps to recongratulate him and this also works to move the call towards closing. ${ }^{7}$

Importantly, although alternative recognitionals are commonly deployed in complaint environments, this practices is not one that does complaining. This case shows that alternative recognitionals can be embedded in different sorts of action. Here, it works to simultaneously reinvoke closings and to recongratulate the recipient. This form of alternative recognitional emphasizes the closeness of the speaker and addressee even where the action involved is otherwise disaffiliative. 
A second example underscores the variety of actions that alternative recognitionals can be used to accomplish. In this case through her use of "the birthday boy" rather than her son's name in line 1, Nicole better fits her referring expression to her request that her mother pick up her son from a local swimming pool. Embedded is an account for her request and for why it should be granted: it is the boy's birthday.

(12) HS 7-23-03 T1 49.13

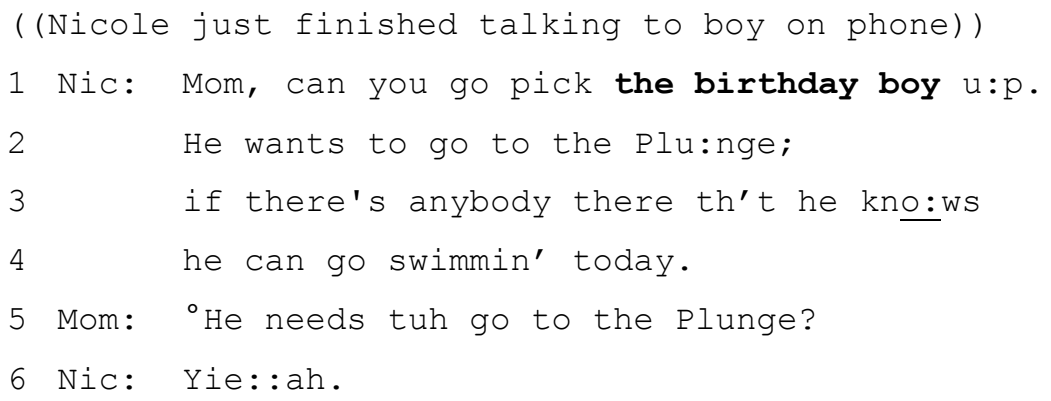

Recognition is not always achieved on an initial "in the know" reference (we saw this problem earlier in Extract 3 for a different type of alternative recognitional). For instance, see Extract 13. Here, Leslie initiates a telling to Joyce in line 1. The alternative recognitionals are in line 9 and 12. The unmarked referring expression for this person would almost certainly be his first name. Both forms used here "Your friend "n mi:ne" and "Mister: R:," appear to be of the variety that you must "know" who is being referred to. This case is stronger than the others shown in this section since whereas the others are very context dependent, this one is less so. Thus, this one even more strongly requires the recipient to recognize the referent from a marked form of reference.

\section{(13) Holt 2 C85-4}

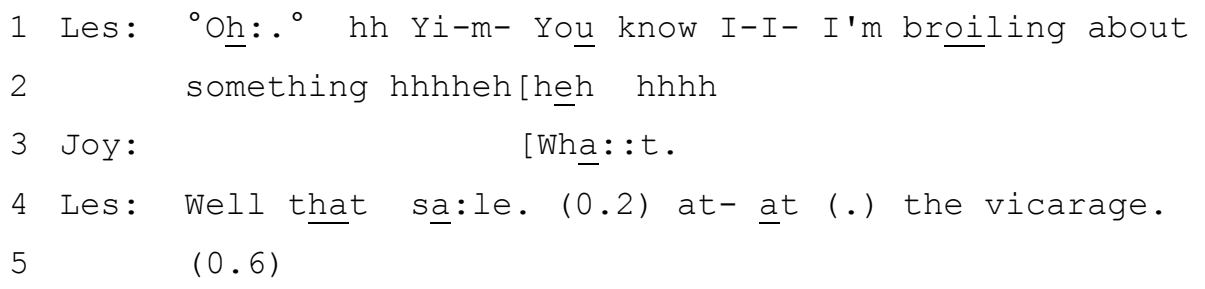




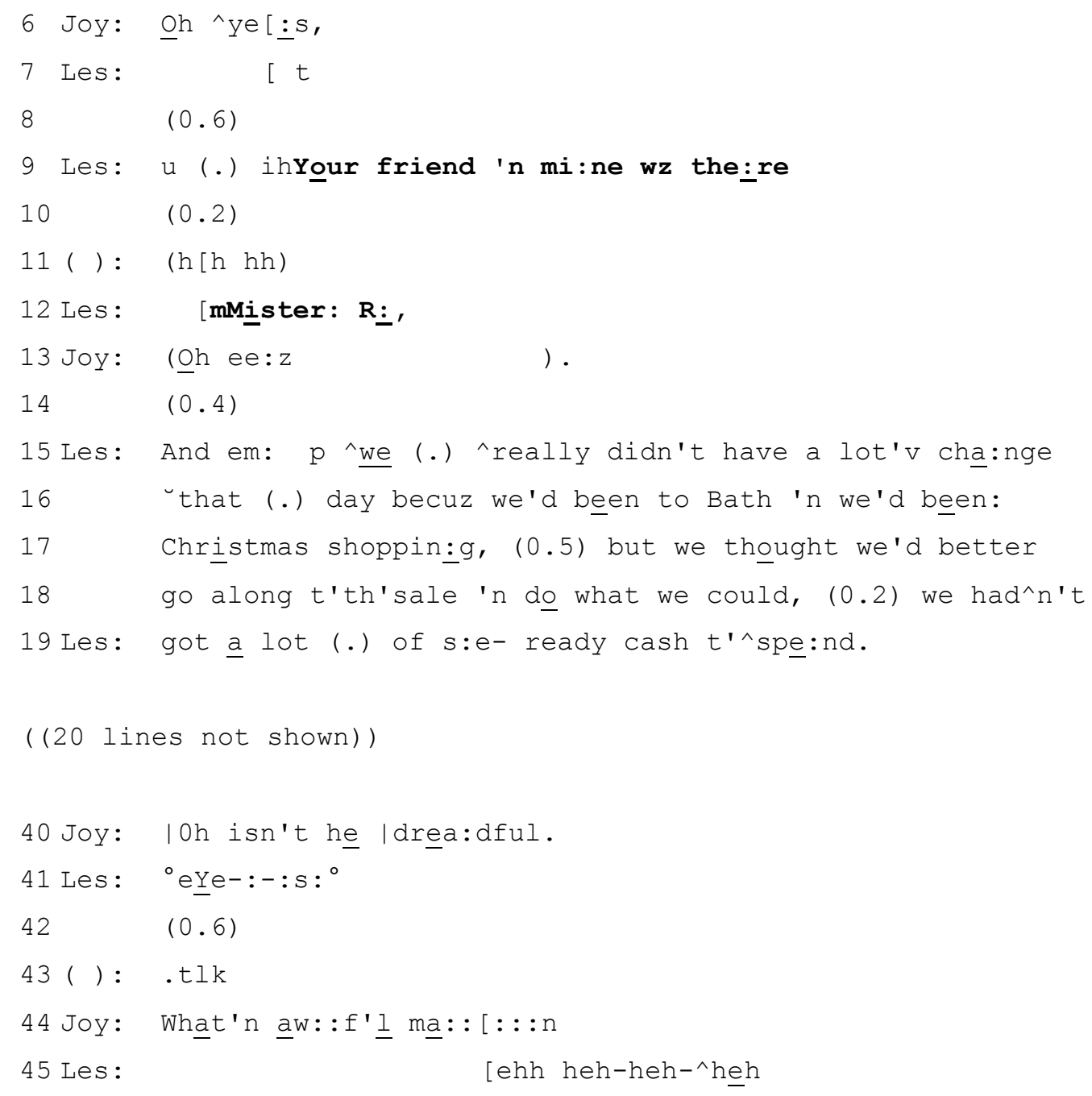

Leslie is complaining. She projects this in her pre-announcement (Terasaki 2004) at lines 1-2 to which Joyce gives a go-ahead in line 3. Here Leslie seeks recognition of an event "that sa:le." which fails to get recognition. She adds an increment which, after some delay, does receive an upgraded claim of recognition. Having achieved recognition of the event, Leslie then makes an announcement, part of which is delivered not as the complaint itself but which, through the person reference, conveys that this individual is in some way tied to the complaint. This is the first and most important alternative recognitional. It is placed at a point where the addressee knows that this person both made her angry and could be somehow connected to the sale at the vicarage and that Leslie could think that Joyce would be able to recognize this person from this reference formulation. However, there is no uptake. In line 12 a second try is offered. Again Leslie 
offers an alternative recognitional. Although this is very similar to a name, it is both a marked form for a name (Mister X) and it is not offered as a name but as a sort of code through the use of only one letter " $\mathrm{R}$ ". This achieves recognition after which Leslie goes on to deliver her complaint. Joyce conveys her understanding of the complaint as leveraged against this individual in lines 40 and 44.

Here again, the action in which the speaker is engaged is giving a complaint. The alternative recognitional helps accomplish this action, and here (where that was clearly projected through the pre-announcement) it is used to provide an account for the complaint: that this individual is responsible for the complaint. It also conveys further information about why this is a complainable matter: namely, that this is someone who treats her and others badly. Thus, this dimension of him is captured as a complainable matter through this reference prior to that being conveyed through the telling of which it is part.

A third instance is shown in Extract 14. Here an elderly Danish woman (P) is being assisted in her hygiene by two home help staff (HH1 and HH2) who see her regularly. $\mathrm{P}$ has been complaining that they are causing her pain. This prompts $\mathrm{HH} 2$ to tell about problems they had with the woman the day before when HH1 was not present. Here, $\mathrm{HH} 2$ refers to $\mathrm{P}$ (who is present) as Fruen "Madam" (line 4) as part of doing a complaint about $\mathrm{P}$.

(14)

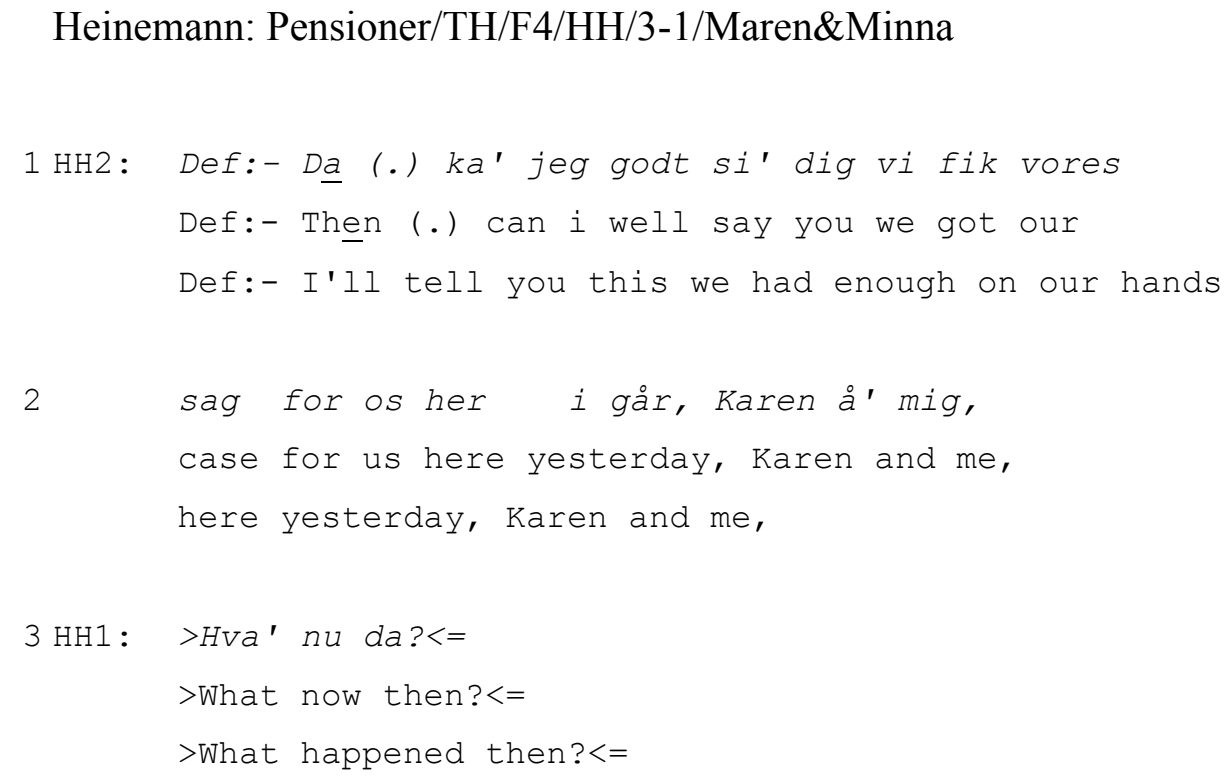




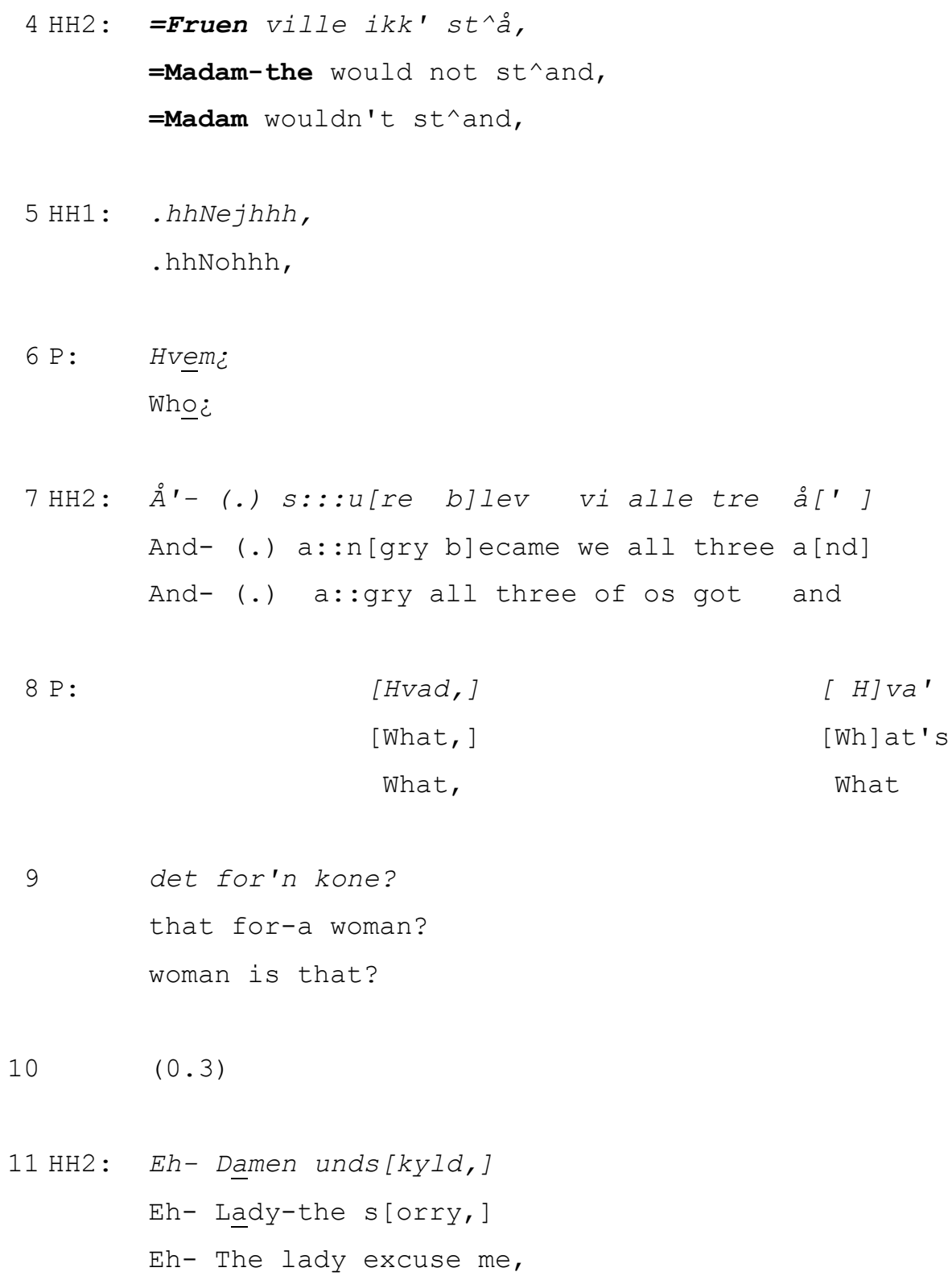

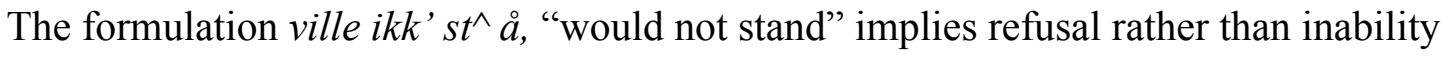
(something that $\mathrm{P}$ later quarrels with), and this assists with the action being hearable as a complaint. In Danish, agreements to a negatively framed utterance are typically done with a negative (Heinemann 2005). Thus, in HH1's immediate uptake .hhNejhhh, “.hhNohhh," she affirms HH2's compaint as expectable (ibid). In this way although she does not treat the announcement as news, she does affiliate with it as a complainable. 
The reference form here assists with projecting and accounting for the complaint by pointing to one reason P would refuse: She is not merely a woman but is "Madam": someone who is not (and should not be) made to do things she does not wish to do. We can see that this form of reference causes no problems for HH1 as the primary recipient, but $\mathrm{P}$ claims that it causes her problems (see the initiations of repair in lines 6 and 8-9). But it is unclear whether she is quarreling with being referred to as Fruen or whether she genuinely does not understand who is being referred to. At line 11, we can observe that $\mathrm{HH} 2$ displays an analysis of $\mathrm{P}$ as doing the former and corrects her reference form to Damen ("the Lady") along with an apology.

With this "in the know" reference, $\mathrm{HH} 2$ affiliates herself with $\mathrm{HH} 1$ against $\mathrm{P}$. Here this is accentuated because of P's copresence. Although it does not firmly place P as within anyone's domain of responsibility, by choosing a formulation that requires insight into the speaker's way of thinking in order to figure out who it refers to, the expression, as others in the section have done, works to position the speaker closer to the addressee than an unmarked referring expression would, and, furthermore, closer than other forms of alternative recognitionals would.

This section offered instances of a fourth type of alternative recognitional. These cases all involve references that require the addressee to "figure out" who the referent is. This was not the case in the other sections. In these cases I argue that by offering a person reference form that requires some sort of additional common ground or is in some way more context dependent, the speaker positions him/herself more closely to the addressee through the person reference form. This may be a resource that is used when the action is otherwise disaffiliative with the addressee as a way of mitigating the strength of that disaffiliation. However, it need not be used exclusively in such environments.

\section{Discussion}

This chapter has demonstrated that the alternative uses of person reference forms are not only about achieving recognition. In line with Schegloff (1996a), this chapter shows that when speakers use marked reference forms where unmarked references are available and known to the participants, more than simply referring is being done. We have seen that 
even when an alternative recognitional risks failing to achieve recognition due to the potential ambiguity of the referent, this type of reference may still be used (e.g., Extracts 3 and 13). This chapter advances existing work on the system of person reference by examining the question of what "more" speakers are doing. The argument here has been that whereas unmarked reference forms (most commonly names in English) are neutral with respect to the action being deployed in the speaker's turn, alternative recognitionals are designed to be fitted specifically to the action in which they are embedded and therefore to work to convey the action and/or account for it. This analysis holds across all four types of alternative recognitionals: addressee associated; speaker associated; demonstrative prefaced descriptions; and "in the know" reference forms. Each of these appears to be designed primarily to manage the relationships in the three-way triangle between the speaker, addressee, and referent.

With addressee associated cases, we observed that the form explicitly associates the referent to the addressee thereby working to place the referent within the domain of responsibility of the addressee. Secondarily, this may work to disassociate the referent and the speaker (though this is a by-product rather than a primary effect). We might depict this as in Figure 1.

$<$ FIGURE 1 HERE $>$

With speaker associated cases the analysis is nearly inverted. The speaker explicitly associates the referent to him/herself and through this, positions the referent within the speaker's own domain of responsibility. Thus, this alternative recognitional format emphasizes the closeness of the speaker and the referent. We can further observe a secondary effect of disassociating the referent and the addressee. This is depicted in Figure 2.

$<$ FIGURE 2 HERE $>$

In demonstrative prefaced description examples, the demonstrative determiner works to disassociate the referent from both the speaker and the addressee. Thus, he/she 
is placed outside of the domain of responsibility of both interactants. This form primarily distances the referent from both speaker and addressee and secondarily invokes relatively greater closeness between the speaker and addressee as it invokes their shared position relative to the referent. This is shown in Figure 3.

\section{$<$ FIGURE 3 HERE $>$}

Finally, the "in the know" references appear to be neutral with respect to placement of the referent in a domain of responsibility. But, they affirmatively invoke the relative closeness of the speaker and addressee by requiring greater knowledge and understanding between the two parties in order to make sense of the referent. This is shown in Figure 4.

$<$ FIGURE 4 HERE $>$

This chapter supports prior work arguing that person reference in social interaction is clearly organized with respect to three preferences (Sacks \& Schegloff 1979; Schegloff 1996a):

1) To fit the referring expression to the recipient so that he/she will recognize the referent; 2) To use the minimal number of required referring expressions (preferably one); and 3) To use a name over another referring expression when possible. This chapter has further examined what speakers are doing when they deviate from these preferences. The main finding is that when speakers deviate from the unmarked reference form, they fit the reference form to the action in which the reference is embedded. This practice then works to convey the action and to account for it, and it at least partially accomplishes this through the positioning of the referent vis a vis the speaker and addressee's domains of responsibility. This chapter also contributes to the growing body of work arguing that in interaction, persons are very concerned with epistemic territories (Clift 2005; Heritage 2002a, 2002b; Heritage \& Raymond 2005; Kamio 1997; Schegloff 1996b; Stivers 2005). Coming from a Western European perspective, we might not initially expect persons to be a category that can be placed within or outside of a particular knowledge domain or 
territory. However, the practice documented here suggests that this is in fact the case and that people are exploiting the structure of both the language and the cultural system to do epistemic work. 


\section{Acknowledgements}

This chapter benefitted greatly from the input of my colleagues. In particular I'd like to thank Rebecca Clift, Maria Egbert, Nick Enfield, John Heritage, Manny Schegloff and Jack Sidnell for comments and discussions that shaped the analysis presented here. Thank you to Trine Heinemann and Federico Rossano for particularly useful examples. This paper was given at the Dutch Sociolinguistics conference in Spring, 2006.

\section{Notes}

${ }^{1}$ But see, in particular, Brown (this volume) and Hanks (this volume) for discussions of cultural variation.

${ }^{2}$ I will not examine cases of first or second person reference though examples appear quite similar (e.g., when the speaker refers to himself as "the dealer" or when the speaker refers to the addressee as "the chef"). Similarly, I will not examine subsequent position references though in the data I have examined, alternative recognitionals appear there as well (e.g., after talking about someone by name he is subsequently referred to as "the hot guy").

${ }^{3}$ I use the term "unmarked" in the pragmatic sense. This refers to the more typical, expected, and canonical usage where more than one possibility exist for a given context. Enfield (this volume) discusses markedness more fully. Also see Levinson (2000) and Comrie (1996).

${ }^{4}$ Kin titles such as "Dad" used by a speaker to her mother to refer to the speaker's father were considered names whereas "my dad" used to refer to the speaker's father but to a friend was considered a kin term.

${ }^{5}$ Also observe that this person reference was done on repair. That is, the first turn constructional unit (TCU) (Sacks, Schegloff \& Jefferson 1974) targeting a person reference was aborted with "uh:" and the entire unit was redone with "Where's your guy. ..". One possibility is that had Stanley placed "your guy" in the TCU following the vocal hitch "uh:" this would have been vulnerable to being heard as a trouble with accessing 
the name (return to Extract 2). The redoing of the query in this way may work to emphasize this as an alternative recognitional rather than as a descriptive recognitional being used because a name was not available for that moment.

${ }^{6}$ Note that I am not dealing with anaphoric usage here. I am dealing exclusively with initial mentions of a referent that are treated as initial references.

${ }^{7}$ Edgerton appears to additionally hear this as a possible complaint against his wife in that he accounts for her current activities in lines 7-9 (perhaps accounting for her not speaking with Billy though there was never a declination to do so). 